\title{
ETNOGRAFIA DE UMA EXPOSIÇÃO DO MUSEU DA ARTE CONTEMPORÂNEA DO CEARÁ
}

\author{
Maíra Rocha Rufino*
}

O processo de legitimação das/os/es artistas negras/os/es em espaços institucionalizados de arte é foco desta pesquisa que tem como lócus o Museu de Arte Contemporânea do Ceará (MAC/CE) e em que a sociologia da arte é tomada como ferramenta teórico metodológica. Busca-se aqui, portanto, apresentar parte da pesquisa em curso na nomeada instituição a fim de compreendermos quais são estes mencionados processos de legitimação, neste caso, através da etnografia de uma das exposições que estiveram recentemente no MAC/CE. Este recorte compreende o período entre Outubro de 2019 e Fevereiro de 2020, etapa inicial da pesquisa de Iniciação Científica (FUNCAPUECE), que permanece em curso.

Palavras-chave: Arte Contemporânea; Sociologia da Arte; Artistas Negras/os/es; Legitimação; Metodologia.

\section{INTRODUÇÃO}

Quais os processos para a permanência de uma obra no Museu da Arte Contemporânea do Ceará (MAC/CE)? Inicio com esta pergunta porque estou interessada em compreender quanto tempo leva para uma obra permanecer em um equipamento cultural, em específico, no MAC/CE. Além do processo de legitimação enfrentado pelas/os/es artistas e coletivos para a exposição de seus trabalhos em espaços institucionalizados de arte, é importante entender quem determina a permanência de seus trabalhos: É o público? É a curadoria? É o conteúdo da obra? Ela incomoda? Quem está mais interessada/o/e na sua circulação? Tenho muitos questionamentos e vou tentar colocá-los em diálogo com algumas/uns autoras/es/es. O objetivo aqui é levantar questionamentos a partir da pesquisa de iniciação científica em curso que tem no MAC/CE o seu lócus. Creio que tais questões sejam necessárias ao campo das artes visuais local, principalmente pelo conteúdo específico da exposição Zona de Remanso, aqui focalizada, que versou sobre os processos de colonização; assim, sua construção histórica através do conhecimento e sua relação com o próprio MAC/CE será tratada a partir da teoria

\footnotetext{
* Universidade Estadual do Ceará, Av. Dr. Silas Munguba, 1700 - Itaperi, Fortaleza - Ceará, CEP60714-903, Brasil. E-mail: mairaabreurocha@hotmail.com

(D) https://orcid.org/0000-0002-1183-9851
} 
interpretativa de cultura e seus símbolos, levando em consideração as intervenções na exposição feitas pelo público e outras/os/es artistas da cidade de Fortaleza (CE).

A pesquisa tem se relacionado com o campo da sociologia da arte voltando-se à compreensão de quais são as regras do mundo da arte, em específico no MAC/CE, acerca da arte contemporânea, uma categoria analítica importante e em disputa no campo da arte. Deste modo, muitas questões permeiam a pesquisa, como as que iniciei esse relato, assim como a questão central que conduz a pesquisa: quais os processos de legitimação que as/os/es artistas negras/os/es têm enfrentado nas artes visuais para expor no MAC/CE?

O período ao qual referencio a minha pesquisa é de Outubro de 2019 até Fevereiro de 2021, a partir de dados retirados das fichas e catálogos das exposições, do próprio acervo do museu (e acervos de outras instituições as quais o museu mantém guarda), bem como a própria exposição, a qual direciono meu olhar nesse período no MAC/CE. Gostaria de evidenciar que a exposição Zona de Remanso, a qual faço uma análise junto de questionamentos surgidos durante meu acesso ao equipamento, foi retirada precocemente do Museu. Em um primeiro momento - quando iniciaram-se as intervenções construídas pelas/os/es autoras/es do trabalho que faziam críticas à própria gestão do equipamento -, a exposição foi fechada, algumas semanas depois foi reaberta. Logo em seguida retirada juntamente com outros trabalhos que tinham relação com o tema.

Esta pesquisa de Iniciação Científica (bolsa FUNCAP-UECE), onde sou bolsista do Professor Doutor Guilherme Marcondes, está vinculada ao projeto de pós-doutorado do docente: Legitimação, Disputas e Narrativas dos(as/xs) Artistas Visuais Negros(as/xs) da Arte Contemporânea, tratando-se do subprojeto: Sobre Apagamentos e Consagrações: Artistas Negros/as/xs e a Memória Cearense. Neste subprojeto estamos elaborando um mapeamento que permitirá a compreensão de quem são as/aos/es artistas que expuseram e estão presentes no acervo do MAC/CE. Assim, a partir desse levantamento será possível realizar estudo de caso da trajetória das/os/es artistas negras/os/es com produções ligadas à arte contemporânea que fazem parte da memória cultural cearense presente na instituição. Deste modo, objetiva-se compreender os processos de reconhecimento e legitimação das/os/es artistas negras/os/es.

\section{CULTURA COMO QUESTÃO}

Iniciarei com uma abordagem do conceito de cultura por Clifford Geertz (19262006), que defende o conceito a partir de Max Weber (1864-1920), assumindo que a cultura 
é uma teia tecida pelo próprio homem. Partindo, assim, não para a ciência experimental em busca de leis e, sim, da busca por significados contidos na ciência interpretativa. "É justamente uma explicação que eu procuro, ao construir expressões sociais enigmáticas na sua superfície" (GEERTZ, 1926, p. 4). Seria, então, um momento de entender o movimento que a exposição Zona de Remanso fez quando questionou o papel da branquitude na cultura cearense, quando indagou o público da seguinte forma:

Os trabalhos se debruçam sobre o litoral cearense, um território complexo banhado pelo Atlântico, e as implicações que nos tomam entre mergulhar no conflito, banhar-se e queimar-se sob o sol, inscreve-se na poesia das ondas ao passo que se impõe a urgência de atravessar uma história cindida. Nessa experiência, os corpos des artistas são atravessades pela imensidão das águas. E se tornam imenses também. Zona de Remanso traz questões sobre como as relações com o Oceano Atlântico vêm sendo orquestradas globalmente: extrativismo das riquezas de suas águas, nas recentes aparições de petróleo em nossa costa, no cruzamento dos navios de assaltantes europeus em direção à América, na expropriação e capitalização de recursos naturais e na consequente devastação criminosa de inúmeras espécies (ZONA DE REMANSO, 2019/2020).

Se Geertz nos coloca diante de inúmeros significados sobre a cultura podemos, então, a partir dessa exposição entender como a cultura eurocêntrica construiu bases sólidas em nossa cultura local, como também nacional, passando pelo processo de colonização, dominando a população por meio da violência e buscando o silenciamento das culturas dos povos originários do país, bem como das populações negras sequestradas e escravizadas em território, hoje, brasileiro.

Zona de Remanso, criada por Cadena, Clébson Oscar, Larissa Vasconcelos, Linga Acácio, Jonas Van, Priscilla Sousa, Karine Araújo e Zahra Alencar. Um trabalho que pode estar caracterizado em uma exposição interativa, em que foram propostos diversos espaços para que o público visitante pudesse deixar suas impressões, inclusive para que questionasse seu grupo social e os privilégios a ele relativos. Um dos trabalhos expostos era, portanto, uma urna de acrílico instalada em uma das paredes da exposição onde existia a seguinte frase, "Espaço para a branquitude deixar em dinheiro seus privilégios" (Fig. 1 DEVOLVA, instalação, 2019), e, assim, propunha o debate sobre as estruturas sociais que excluem as populações mais pobres, as colocando às margens das grandes cidades. 
(Fig.1) | Priscila Sousa: DEVOLVA, instalação, 2019.

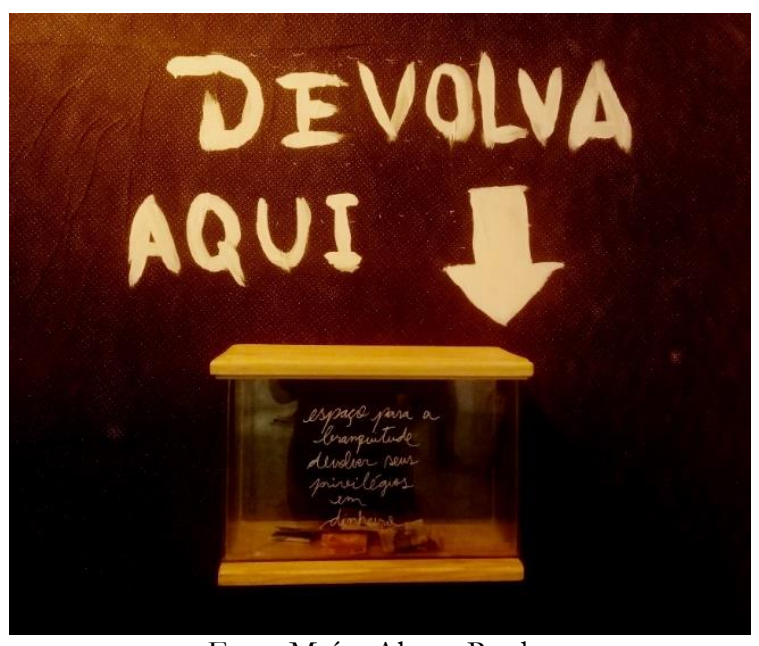

Foto: Maíra Abreu Rocha

Assim, como outro trabalho da exposição, era composto por uma garrafa de vidro com a frase "Vaquinha para comprar privilégios" em cima de um livro com o título "Conhecer" (Fig. 2 - "Molhar eles feito chuva ácida", instalação, 2019). Podemos refletir da seguinte forma: a quem pertence o alto valor aquisitivo no Brasil?; e, para qual grupo social, culturalmente no país, é destinado o acesso ao conhecimento? O próprio espaço do museu pode ser um medidor desse acesso.

(Fig. 2) - Clébson Oscar: "Molhar eles feito chuva ácida”, instalação, 2019. Exposição: Zona de Remanso, 2019.

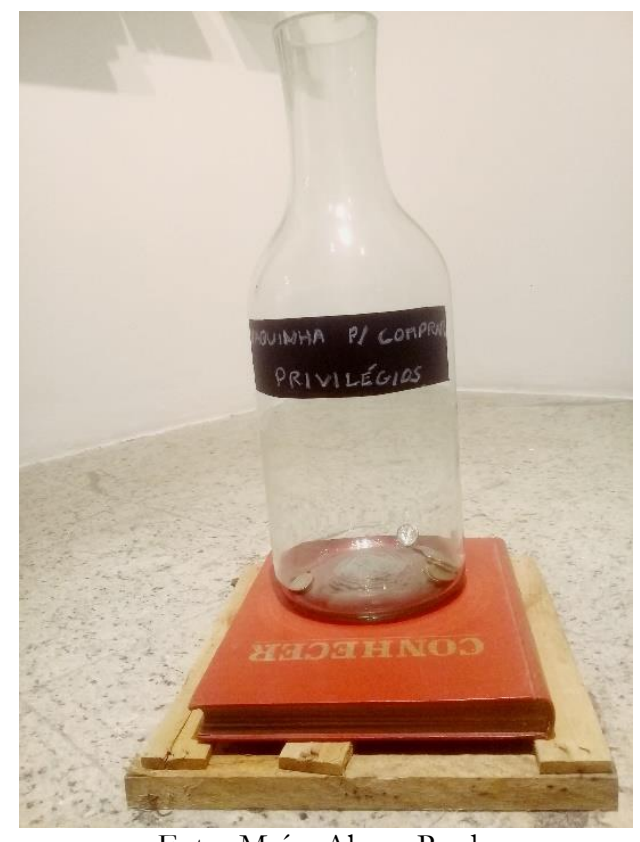

Foto: Maíra Abreu Rocha

Os processos de educação no Brasil direcionam a história para a supremacia branca potencializando o seu local de poder refletido em todos os espaços urbanos. Podemos refletir sobre o processo de educação no Brasil a partir de Abdias do Nascimento (1914- 
2011), em seu livro O genocídio do negro brasileiro: Processos de um Racismo Mascarado (1978). Onde o autor pontua a estruturação da escravização no Brasil que contribuiu/contribui para as tentativas de anulação histórica das lutas e resistências do povo negro em diáspora, injetando no imaginário social, o mito da democracia racial para justificar as violências a partir da história da colonização. Percebemos nos livros de história, este sendo um indicador pautado no objeto da exposição, como mecanismo do embranquecimento cultural da população negra e seu controle social:

Em adição aos órgãos do poder - governo, as leis, o capital, as forças armadas, a polícia - as classes dominantes brancas têm à sua disposição poderosos implementos de controle social e cultural: o sistema educativo, as várias formas de comunicação de massas - a imprensa, o rádio, a televisão - a produção literária ; todos esses instrumentos estão a serviço dos interesses das classes no poder e são usados para destruir o negro como pessoa, e como criador e condutor de uma cultura própria (NASCIMENTO, 1978, p. 93).

Há, na fala de Abdias do Nascimento, uma contextualização nítida de como o processo colonial construiu uma base sólida por meio do conhecimento na construção de certa imagem sobre negros descendentes no Brasil. Permanecendo uma constante "confrontação com o sistema dominante, concebido precisamente para negar suas funções e fundamentos, destruir ou degradar suas estruturas" (NASCIMENTO, p. 94). É nessa dinâmica violenta que a educação colonizadora se transforma em um mecanismo de controle estruturada na discriminação cultural, estando presente em todos os níveis do ensino brasileiro "elementar, secundário, universitário", tornando-se presencialmente forte e naturalizando o apagamento cultural do povo negro. Galgada em uma miscigenação cultural fortalecida pela branquitude em todo o âmbito social se valendo da mesma para justificar o fortalecimento da raça pura, que poderia estar sofrendo uma espécie de golpe dominante articulado pela polução negra que sonha fortemente em tomar as terras brasileiras. Permanecendo, insistentemente, o uso do discurso da luta contra a contaminação da cultura dominante, no caso a eurocêntrica, valendo-se de todas as formas de violência, até as mais silenciosas, como a institucional.

Compreendo aqui o espaço do museu como um reflexo dos locais de poder que atravessam os processos de legitimação das/os/es artistas. Quem expõe nos museus? Qual o perfil das/os/es artistas que logram expor em tais espaços institucionalizados das artes visuais?

Em sua tese Arte e consagração - Os jovens Artistas da Arte Contemporânea (2018), Guilherme Marcondes dos Santos, nos dá um panorama sobre os processos de legitimação de jovens artistas nas artes visuais no Brasil, auxiliando, portanto, também o 
entendimento do contexto cearense, através do Museu da Arte Contemporânea (MAC/CE). O autor faz uma relação entre os processos que envolvem a curadoria e a crítica, para isso constrói uma análise partindo da própria história da arte, a partir da Arte Moderna, que teria a legitimação fortemente enraizada na crítica de arte, e a Arte Contemporânea, em que a curadoria de exposições seria uma função legitimadora por excelência. Assim, podemos entender melhor no campo da arte contemporânea como acontecem as ações dos sujeitos sociais e os critérios que envolvem atualmente a categoria jovens artistas:

\begin{abstract}
Mais que uma corrente artística, a arte contemporânea pode ser entendida como uma configuração de regras que surge no século $\mathrm{XX}$, o qual igualmente assistiu o advento da multiplicidade de movimentos artísticos que compõem a complexa história da arte moderna. Refletir sobre as noções de artista e obras de arte em ambos os referidos períodos de produção artística (moderno e contemporâneo) auxiliará a demonstração de quais regras vigentes nesses diferentes momentos da história (ocidental) da arte, trazendo um enfoque no contexto brasileiro (MARCONDES, 2018, p. 41).
\end{abstract}

Aqui podemos pensar os dois segmentos de arte: Moderna e Contemporânea, a partir de seus paradigmas. Segundo Marcondes (2018) as técnicas da Arte Moderna, utilizadas pelos diferentes artistas, seriam uma diferenciação do que lhes precedera, mas apesar disto, nem todos os modernistas estavam na mesma sintonia. Apesar de proximidades e diferenças, muitos movimentos artísticos receberam de teóricos da arte a alcunha de modernistas e, assim:

Fato é que as disputas e consensos, as rupturas e continuidade, não eram travadas apenas com relação ao passado, sendo igualmente travadas com o presente: todos voltavam-se para o futuro e nele buscavam inserir a si e suas práticas, essas como as mais promissoras para o futuro da arte (MARCONDES, 2018, p. 45).

Dessa forma, a consagração passa pelo processo de reconhecimento, relação mútua para que alguém reconheça o trabalho buscando a/o/e artista inserir a si e suas práticas no campo da arte, dessa forma, a Arte Moderna realizou, podemos dizer, uma revisão das regras da arte. Seriam as rupturas, consensos, disputas e continuidades o caminho para um "novo olhar", inaugurando a Arte Moderna, "obrigando" a criação de novas regras para o mundo das artes. Surgindo o olhar para o artista, "antes visto como um ser que representava a realidade", alterando seu estatuto dentro de novos parâmetros e regras.

Se as regras são alteradas no Modernismo pela necessidade artísticas de outros olhares diante das obras, na Arte Contemporânea é necessária uma reformulação desse conjunto de regras. Agora, "o status de obra é atribuído pelo ato do artista”, onde surge o pluralismo com diferentes estilos e técnicas que podem se entrelaçar. Nesse contexto, 
novas práticas artísticas implicam em novas instituições, regras e atores sociais para a legitimação de suas práticas, assim enfatiza Marcondes (2018).

Há também na Arte Contemporânea a provocação da mudança de postura no público, que passa agora a interagir diretamente no trabalho das/os/es artistas, rompendo com barreiras entre arte e vida. Surge nessa mudança de paradigmas uma maior mediação entre público, textos de críticos, curadoria, instituições de arte e o trabalho:

Todavia, é necessário destacar os processos de mediação entre o público e a obra que, por exemplo, incluem: textos de críticos, de curadores e das instituições museais. Assim, não é possível tratar de uma experiência subjetiva isenta por parte do público. Ou seja, há apesar da fala acima, um processo de legitimação, compreensão e construção das obras, que por mais que seja desejoso (por parte de artistas e curadores) que o público experimente/vivencie as obras sem interferência dos seus autores, estas interferências se fazem presentes, pelo simples fato de tais obras estarem, por exemplo, presentes em espaços museológicos (MARCONDES, 2018, p. 58).

É necessário que observemos estas regras para tentar acompanhar o ritmo que a arte contemporânea ganhou até aqui, desta forma também entender em quais contextos históricos ela foi construída para que possamos perceber a relação do perfil das/os/es artistas que tomamos como foco na investigação.

Gostaria de retomar ao conceito de cultura elaborado por Geertz, em seu livro A interpretação das culturas (1973), que se refere a teoria interpretativa da cultura. Onde, Geertz, define a cultura como pública, para tanto, sendo o comportamento humano visto como ação simbólica. É neste ponto que o questionamento sobre a branquitude, na exposição, relata a ação simbólica do comportamento humano. Em um outro espaço da exposição Zona de Remanso, estão alguns livros de história colonial, onde o colonizador é retratado como um herói salvador do Brasil, desbravador dos mares que por recompensa de seu bem feito merece levar todas as riquezas que encontra pela frente. Um livro com a figura da princesa Isabel colocada no processo colonial brasileiro como a mãe dos pobres (Fig. 3 - "Molhar eles feito chuva ácida", instalação, 2019). Sobre os livros de história uma faixa com a seguinte frase: "A branquitude está aqui neste momento, sua presença é real". Ela, a frase, exala por todos os espaços, nos livros de história como objetos da exposição evidenciam o silenciamento das violências que fizeram a família real "ascender na terra próspera". Ademais, devemos indagar qual é a importância dos museus entendendo os significados de cultura e seus múltiplos papéis. 
(Fig. 3) - Clébson Óscar: “Molhar eles feito chuva ácida”, instalação, 2019. | Exposição: Zona de Remanso, 2019.

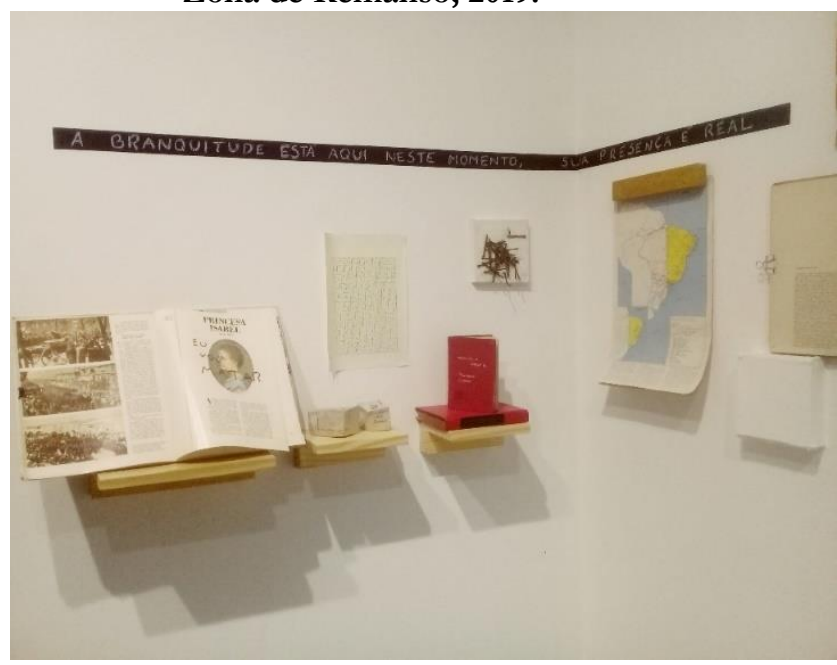

Foto: Maíra Abreu Rocha

Percebemos que existem códigos os quais atravessam a estrutura museológica, ou seja, ações humanas foram construídas em raízes densas, para isso, ela não é tal e qual como "vista pela primeira vez"; ela é mais profunda. "Todavia, é importante no tocante a essa observação que um ser humano possa ser um enigma completo para outro ser humano" (GEERTZ, 1926, p. 10). O comportamento deve ter foco na análise, pois é através de seu fluxo, na ação social, que se encontram as formas de articulações da cultura.

Analisando a cultura local por meio de seus dados históricos, poderemos traçar um perfil a partir da análise dos trabalhos e coleções das/os/es artistas que expuseram no MAC/CE, mas por agora o foco está sendo na exposição Zona de Remanso (2019), que nos possibilita entender algumas nuances do próprio equipamento. O Museu da Arte Contemporânea (MAC/CE), um equipamento do Centro Dragão do Mar de Arte e Cultura, fomentado pelo Governo do Estado do Ceará, localizado na capital, Fortaleza, sendo um dos principais espaços institucionalizados de arte do estado. Contendo mais de mil obras em seu acervo, realizando exposições temáticas e campanhas de ampliação de seu acervo permitindo pesquisas. Tendo sob sua guarda, além do próprio acervo, o da Pinacoteca do estado do Ceará, que dentre os/as/es artistas conta com obras do pintor Antonio Bandeira, servindo assim de grande referência e importância nacional.

\section{A VISIBILIDADE DO POVO NEGRO NO ESTADO DO CEARÁ}

Inicio aqui uma breve análise de como foi construído no imaginário cearense a negação do povo negro e como atualmente a população negra vem se reconhecendo dentro do estado a partir de dados da população desde o século XIX, apresentados pelo 
historiador Eurípedes Antônio Funes em seu livro Uma nova história do Ceará (2000) e da apresentação de dados do último censo (2019). Levando também em consideração a frase do senso comum local: "no Ceará não tem negro", problematizada por Funes.

As questões postas pelo autor nos levam para o entendimento das tentativas de embranquecimento da população no estado, negando a existência negra a partir do argumento de que no Ceará o processo de escravização do negro foi mais brando, assim como cita, Abdias do Nascimento (1914-2011), em seu livro O genocídio do negro brasileiro (1978), escancarando a estrutura colonizadora a nível nacional que anula a história de lutas e resistência do povo africano em diáspora colocando o Brasil, dentro da América Latina, como o país onde a "forma branda de escravização" foi pacífica ao povo negro:

\begin{abstract}
Outro dos mitos de conveniência inventados para mitigar a consciência de culpa do opressor e minimizar acusações contra ele, é o mito que apregoa um alto grau de bondade e humanidade na escravidão praticada na católica América Latina: as colônias espanholas e portuguesas; nestas, o caráter do regime escravocrata seria o oposto daquele existente nas colônias inglesas na América, especialmente nos Estados Unidos. Este mito, tão propagado nos séculos passados, ainda hoje tem seus adeptos (NASCIMENTO, 1978, p. 51).
\end{abstract}

No Ceará não foram diferentes as tentativas de apagar da história as lutas e conquistas do povo negro, onde podemos entender a herança da estrutura colonizadora deixada por aqui, por tanto, foco da exposição Zona de Remanso, quando traz artistas que questionam o papel da branquitude a partir de seu território: o litoral fortalezense. Podemos refletir sobre a necessidade de um estudo mais delicado sobre a frase "no Ceará não tem negro" citada por Antonio Funes. O autor nos apresenta que, ainda que no estado do Ceará a abolição tenha ocorrido anteriormente, em 1884, do que no restante do país (1888), podemos perceber que a liberdade não foi completamente adquirida pela população negra, pois estava personificada por intermédio de mecanismos de controle construídos sobre a falsa abolição. Por aqui, um canal de comunicação o jornal O Libertador, fundado em 1881, mostrava a indignação por parte dos abolicionistas com a escravidão, e, sendo, um grande formador de opinião para a época conseguiu atrair segmento significativo da sociedade civil para a causa, gerando mais tarde, o alforriamento dos escravizados. Mas, a verdade é que na prática a população cativa continuo exercendo trabalho escravizado para seus "senhores". Para a população negra a condição de "pessoa livre" era apenas uma negociação. "Jubilava-se com as alforrias, tanto aquelas com ônus, em que o senhor recebia o valor do escravo pago pelo fundo de emancipação, por terceiros ou pelo próprio cativo, e em especial aquelas alforrias concedidas sem ônus" (FUNES, p. 130). Construindo uma forma de garantia da posse sobre o corpo escravizado que permanecia coisificado após a 
abolição. Os processos abolicionistas no Ceará expõem a legitimação da exclusão social camuflada no discurso de liberdade da população negra. Tanto quanto, após esse período, as tentativas de anulação de sua presença no estado, jogando-a à margem da capital (Fortaleza) sem qualquer tipo de assistência. Para 'os libertos", restavam-lhes a potencialização na construção de estratégias de resistência a partir de seu universo cultural, sua história e identidade. "Um fazer histórico que tem passado despercebido aos olhos da intelectualidade e da sociedade" (FUNES, p. 132). Ademais, percebemos mais uma tentativa de embranquecimento da população, na anulação da presença de pessoas negras e sua produção cultural:

No início do século XIX, a presença de afro-brasileiros já era significativa por estas terras cearenses, onde negros e pardos libertos somavam $60,7 \%$ de uma população total de 77.375 habitantes. Neste universo, a população negra e parda cativa, somava 12.254, ou seja, 15,8\% da população (ANTONIO FUNES, 2000, p. 104).

Os dados do censo de 1804, levantados por Funes, revelam que só no Crato (CE) contava-se com uma população de 20.681 habitantes, sendo 67,5\%, formada de pretos e pardos livres e cativos, chegando em Sobral (CE) a serem 72,0\% da população. Ele chama a atenção para o censo de 1818, apresentado pelo governo provincial, onde uma população de 125.878 habitantes, $34 \%$ eram de pessoas bancas; $56 \%$ de pretos e mulatos livres e $10 \%$ eram de indígenas. Já os dados de 1813, revelam que uma província de 131.537 habitantes libertos, " $32 \%$ eram brancos, $7 \%$ índios, $10 \%$ pretos e $51 \%$ pardos":

\footnotetext{
Pelo censo de 1991, o perfil étnico no Ceará continua com o mesmo rosto mostrado pelas primeiras estatísticas, com a presença indígena, que teima em não desaparecer por mais que forças antagônicas tenham se esforçado no sentido contrário, predominando de força ampla um povo de cara mestiçaparda. O total da população apontada por este censo é de 6.366.647, sendo: branca - 1.867.160; preta - 187.750; parda - 4.290.828; amarela - 4.066; indígena - 2.692 e sem declaração - 13.617 “(FUNES, 2000, p. 106).
}

Esses dados passam pelo autorreconhecimento da população enquanto pessoas negras, mas também indígenas, já que no Ceará a população é formada dessas comunidades. Onde podemos perceber que há uma dupla tentativa de apagamento de culturas: a cultura já existente por aqui (indígena) e a da população negra sequestrada de seus territórios.

Os dados do censo de 2019 do Instituto Brasileiro de Geografia e Estatística (IBGE) apresentados pelo Portal G1 CE, nos revela um contraste muito significativo do autorreconhecimento da população negra no estado do Ceará. Segundo o censo, o período entre 2012 e 2018, revela que o índice de 2,9\% passou para 5,3\%, no período analisado, representando uma população de quase 480 mil pessoas, segundo o IBGE. As pessoas autodeclaradas pardas compõem $65,7 \%$ da população e a população declarada branca 
diminuiu - em 2012 eram 30,5\% da população, hoje são 28,2\% - sendo este último um dado que revela que a população cearense tem se declarado não branca. Seria então o fortalecimento do autorreconhecimento da população e desconstrução nas estruturas coloniais, mesmo que lentamente, quando comparado ao crescimento da participação de pessoas negras, se comparado aos outros estados da região nordeste como: Bahia (22,9\%) e Maranhão (11,9\%), destaca a notícia.

O estado do Ceará carrega em seu contexto a estruturação de famílias surgidas das relações entre população negra e indígena, mas é importante perceber delicadamente os dados entre essas formações, pois há nesse contexto uma narrativa da negritude no estado. Após a "extinção" da escravização no Ceará, em 1884, a população negra ainda enfrenta dois processos: seu autorreconhecimento e o acesso de seus corpos nos espaços da cidade. Até a atualidade o discurso de "no Ceará não existe negro" se perpetua. Ademais, é um argumento que abranda a escravização no estado, colocando a população negra como passiva e preguiçosa. "Não se trata de polarizar a escravidão brasileira, e em especial a cearense, entre suave ou rígida, branda ou violenta, mas perceber que esses aspectos passavam todo o regime escravagista" (FUNES, 2000, p. 118).

\section{A ARTE CONTEMPORÂNEA E UM NOVO PARADIGMA}

Agora gostaria de falar sobre as intervenções no Museu por meio da pichação. Após algumas semanas (no período em que a exposição permaneceu no museu), as/os/es artistas que compunham a exposição Zona de Remanso autorizaram outras/os/es artistas a intervirem nas suas instalações presentes na mostra. Ocorria, simultaneamente, outra exposição na instituição, com o título Grande Circular - também construída por diversos artistas - a exposição tratava do genocídio do povo negro e da demonização das religiões de matriz africana na configuração local e, foi aqui que o picho teve seu espaço nas salas brancas do MAC/CE. Entre as duas salas de exposição tinha uma sala branca de acesso aos espaços, uma espécie de hall de entrada. $\mathrm{Na}$ minha segunda visita contávamos com a seguinte pergunta em formato de pichação: "Agora é arte?" (Fig. 5). 
(Fig. 5) - Intervenção no hall de acesso as duas exposições, 2019.

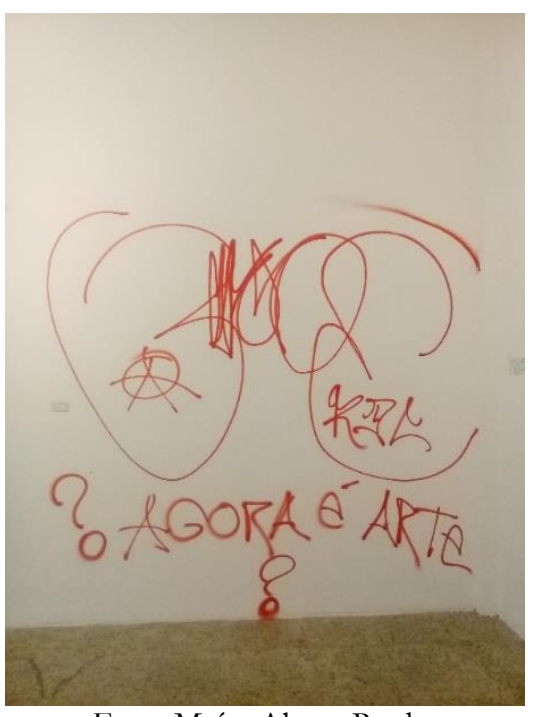

Foto: Maíra Abreu Rocha

As paredes brancas estavam agora cheias de intervenções que denunciavam o incômodo de parte do público do museu com o conteúdo das obras expostas. Frases como "Fogo nos racistas", "A favela vive", "Nós somos perigo", "- Curadoria + Curanderia"; buscavam expor a tentativa da cultura dominante de embranquecimento da arte, especificadamente, aquela que trata do conteúdo das obras que relatavam o cotidiano dos corpos negros e periféricos. Até que ponto a arte agrada? As obras foram criadas para agradar? Qual o perfil dos sujeitos incomodados com as obras expostas? Usarei a perspectiva pragmática nas práticas da Arte Contemporânea a partir de Nathalie Heinch (2014), para que possamos entender o percurso dos olhares incomodados com o conteúdo da exposição, não para justificá-los, mas questioná-los.

Para Heinch, em seu texto Práticas da Arte Contemporânea: uma abordagem prática a um novo paradigma (2014), quando nos reportamos ao campo da sociologia da arte a perspectiva pragmática não pode ser reduzida à demonstração da natureza coletiva das coisas. Porque a abordagem sociológica da arte está para demonstrar qualquer coisa, ou dispensar a natureza individual da experiência artística, está para se propor a descrever a junção íntima entre objetos e ações humanas para que se possa entender o conjunto de estruturas, como representações e valores. É, por isso, que as reações diante das obras expostas dão uma visão de como as regras postas pelas artes em geral, quando ultrapassadas, causam desconforto para quem entra em contato com elas. No caso do picho visto como vandalismo, quando posto em um museu como forma de arte, ultrapassa as regras de estética e aceitação do que seja a arte naquele espaço e para aqueles sujeitos. Nesse processo os sujeitos negam que carregam valores preconceituosos que descendem de uma cultura branca que decide o que é bom: o que vem do próprio branco. Que as artes 
construídas de uma perspectiva periférica, não só as artes visuais, são negativas e não podem ser comercializadas porque não são brancas. Novamente os valores da cultura branca (eurocêntrica) se sobrepõe como cultura dominante e causam a não aceitação de ideias críticas sobre ela mesma. Com o novo status da obra de arte, legado pela Arte Contemporânea e com as diferentes narrativas (no caso aqui analisado, uma advinda da cultura dominante e outra das culturas subalternizadas) os paradigmas entram em conflito.

Heinich (2014), coloca que a obra consiste em todo o conjunto de operações, ações, interpretações provocadas por ela mesma, ocorrendo a não compreensão do que deveria ser compreendido, dentro das regras postas, ficando de fora do entendimento da arte. Portanto, esses conflitos causaram o incomodo com o picho, tanto por parte dos sujeitos apreciadores das obras como por parte de um funcionário que comentou com sua colega de trabalho que "aquilo não é arte". Mas, como a Arte Contemporânea que carrega uma nova perspectiva sobre as necessidades de construção de múltiplos espaços para as artes, pode privar-se da diversidade criativa das/dos/es artistas? "Quanto mais a obra se afasta das expectativas do senso comum, mais necessárias se tornam as mediações entre a obra e o público em geral" (HEINICH, 2014, p.380).

A arte contemporânea, Heinich (2014), apresenta um jogo de limites. Ela rompe com a arte clássica e a moderna, uma "instalação" ou uma "performance" não se enquadram em uma moldura ou em um pedestal, colocando uma diversidade artística onde não há demonstração de vínculo entre obra de arte e interioridade, fugindo das regras dos museus, a rotina econômica e até restauração, sendo assim, com a arte contemporânea há o surgimento de um novo paradigma, transformando completamente o mundo da arte. Então, a chegada de um trabalho em uma exposição é seu estágio final no processo da Arte Contemporânea? Seria seu contexto exposto que define sua permanência no equipamento cultural? Por um lado, a arte contemporânea quebra a lógica traçada anteriormente pela a arte clássica e moderna, por outro, está carregada da cultura dominante que a construiu. Quando um determinado grupo de artistas questiona esse processo em seus trabalhos, usando-se do espaço do museu para criticar sua própria regra, ocorre o conflito que tem como resultado a retirada dos seus trabalhos. Seria o momento de pensar os novos paradigmas a partir dos sujeitos que fazem as regras? O novo paradigma abre espaços no mundo das artes ou seleciona as obras/trabalhos? 


\section{CONSIDERAÇÕES FINAIS}

Podemos iniciar o entendimento do processo de legitimação, disputas e narrativas das/os/es artistas visuais negras/os/es da arte contemporânea no MAC/CE partindo do contexto nacional que, como apresentado aqui, por meio do trabalho de Abdias do Nascimento, está construído estruturalmente, refletindo-se principalmente no acesso ao conhecimento e expressão da cultura, ou seja, na negação de tudo o que não é branco. Portanto, o estado do Ceará é um reflexo de todo o país. O que não devemos fazer é negar a existência das práticas violentas construídas pela branquitude, entendendo que ela está presente também nos equipamentos de arte. Neste sentido, a pesquisa em curso, pode desvelar padrões de legitimação que envolvam também a questão racial, podendo, assim, contribuir para uma reformulação de suas políticas públicas de inserção das/os/es artistas negras/os/es nos espaços legitimados da arte contemporânea. Assim como poderá contribuir para a quebra de paradigmas sociais e reformulação do olhar de seu público sobre os trabalhos de artistas não-brancos.

A apresentação de dados concretos nos mostram quais outros caminhos são interessantes percorrer, diante da possibilidade de se pensar um equipamento plural, formador de novos olhares e atento as políticas sociais. A exposição Zona de Remanso e seu histórico no museu é o início para que eu possa entender como operam as regras da arte contemporânea nas artes visuais dentro do MAC/CE. A mostra é tomada, então, como fio condutor para analisar, posteriormente, dez anos de história do equipamento: entre dois períodos, de 1998-2002 e de 2015-2019. Dados que demonstram as relações construídas pelo Museu desde sua inauguração e como foram (e continuam) se desenvolvendo. Temos nesse contexto dez anos de regras e convenções em um espaço de arte institucionalizado, o qual não podemos negar que está construído em uma sociedade cujas regras foram forjadas no processo de colonização.

Podemos entender como as/os/es próprios artistas se reconhecem dentro dos perfis identificados na análise, isso nos leva a direcionar o olhar para a estética da brancura como define Abdias do Nascimento (1978) em artistas negras/os/es aculturadas/os/es, entendendo como parte dos processos de legitimação o autorreconhecimento e as práticas de "adequação" dentro dos equipamentos de arte:

$\mathrm{Da}$ exposição que estamos fazendo podemos resumir uma definição simples e irrefutável: sem exceção, tudo o que sobrevive ou persiste da cultura africana e do africano como pessoa no Brasil, é a despeito da cultura branco-europeia dominante, do "branco" brasileiro, e da sociedade que, há quatro séculos, reina no país. Os africanos e seus descendentes, os verdadeiros edificadores da estrutura econômica 
nacional, são uns verdadeiros coagidos, forçados a alienar a própria identidade pela pressão social, se transformando, cultural e fisicamente, em brancos (NASCIMENTO, 1978, p. 123).

Discussão, esta, apresentada por Nascimento que analisaremos posteriormente a partir de outros dados que estão sendo construídos com a demografia das exposições e perfis das/os/es artistas que expuseram no MAC/CE, assim como a continuidade da pesquisa em seu lócus principal: o enfrentamento no processo de legitimação dessas/es/es artistas.

No que se refere a exposição Zona de Remanso as/os/es artistas usam de suas obras para evidenciar os obstáculos que encontraram até a chegada no museu. E durante o processo de permanência, denunciar como suas obras sofreram uma tentativa de silenciamento, postas como questionamento da validação de seus trabalhos. Entendo o MAC/CE enquanto espaço de reflexão para a arte contemporânea no estado. Será que o equipamento está preparado para receber a crítica sobre suas políticas? A curadoria teria enfrentado as mesmas críticas que as/os/es artistas durante a exposição? Existe um perfil socialmente construído para as/os/es artistas que expõem no MAC/CE? Estas perguntas seguem conduzindo a investigação que vem sendo realizada e seus resultados serão futuramente divulgados.

Recebido para publicação em 06 de julho de 2020.

Aceito em $1^{\circ}$ de agosto de 2020.

\section{REFERÊNCIAS}

FUNES, Eurípedis Antonio. Uma nova história do Ceará. Fortaleza: Demócrito Rocha, 2000. p.103-132.

GEERTZ, Clifford. A interpretação das culturas. Rio de Janeiro: LTC, 2008. p. 13-41.

HEINICH, Nathalie. Práticas da Arte Contemporânea: Uma Abordagem Pragmática a um Novo Paradigma Artístico. Rio de Janeiro, v.04.02: 373-390, Outubro, 2014.

MARCONDES, Guilherme. Arte e Consagração: Os Jovens Artistas da Arte Contemporânea. Rio de Janeiro, 2018. 365p. Tese (Doutorado em Sociologia e Antropologia) - Programa de Pós-Graduação em Sociologia e Antropologia, Instituto de Filosofia e Ciências Sociais, Universidade Federal do Rio de Janeiro. 
NASCIMENTO, Abdias. O genocídio do negro brasileiro: processo de um racismo mascarado. Rio de Janeiro: Editora Paz e Terra S/A, 1978. 183p.

PAULINO, Nicolas. População declarada negra cresce no Ceará, mas índice é o menor do Nordeste, aponta IBGE. Ceará: G1 CE, 2019. Disponível em: $<$ https://g1.globo.com/ce/ceara/noticia/2019/05/22/populacao-declarada-negra-cresceno-ceara-mas-indice-e-o-menor-do-nordeste-aponta-ibge.ghtml>. Acesso em: 25 de Junho de 2020. 


\title{
ETHNOGRAPHY OF AN EXHIBITION AT THE CEARÁ CONTEMPORARY ART MUSEUM
}

\begin{abstract}
The process of legitimization of black artists in institutionalized art spaces is the focus of this research that has its locus the Museum of Contemporary Art in Ceará (MAC/CE) and in which the sociology of art is taken as theoretical methodological tool. Therefore, we seek to present part of the research in progress at the named institution in order to understand what these processes of legitimation are mentioned, in this case, through the ethnography of one of the exhibitions that were recently at MAC/CE. This cut comprises the period between October 2019 and February 2020, the initial stage of the Scientific Initiation research (FUNCAP-UECE), which remains ongoing.
\end{abstract}

Keywords: Contemporary art; Sociology of Art; Black Artists; Legitimation; Methodology.

\section{ETNOGRAFÍA DE UNA EXPOSICIÓN EN EL MUSEO DE ARTE CONTEMPORÁNEO DE CEARÁ}

Resumen: El proceso de legitimación de los artistas negros en los espacios artísticos institucionalizados es el foco de esta investigación que tiene su locus en el Museo de Arte Contemporáneo de Ceará (MAC / CE) y en la que se toma la sociología del arte como herramienta metodológica teórica. Por ello, buscamos presentar parte de la investigación en curso en la institución nombrada con el fin de entender de qué se mencionan estos procesos de legitimación, en este caso, a través de la etnografía de una de las exposiciones que estuvieron recientemente en MAC / CE. Este corte comprende el período comprendido entre octubre de 2019 y febrero de 2020, etapa inicial de la investigación de Iniciación Científica (FUNCAP-UECE), que permanece en curso.

Palabras claves: Arte Contemporaneo; Sociología del Arte; Artistas negros; Legitimación; Metodología.

Maíra Rocha Rufino - Estudante de Ciências Sociais (UECE). Graduada em Teatro (IFCE). Diretora, dramaturga, atriz e produtora do Grupo Cena Fórum, Caucaia-CE. 